\title{
Systems to establish bioclimatic analogies to predict the area of adaptability of plant species to new environments: The case of Moringa oleifera Lam. in Chile
}

\author{
Fernando Santibáñez $^{1 *}$, Javier Mendoza ${ }^{1}$, Carlos Muñoz ${ }^{1}$, Carolina Caroca ${ }^{1}$, Paula Santibañez ${ }^{1}$, \\ and Loreto Prat ${ }^{1}$
}

\begin{abstract}
Adaptability of a species to new territories is generally assessed by costly trial and error in situ experiments distributed throughout different agroclimatic environments. Nowadays climatic data are available to allow the construction of climatic maps based on data provided through world or local networks of climatic weather stations. The objective of this work was to establish a bioclimatic protocol, based on current and available sources of climate information, to make rapid surveys of suitability for plant species in a given environment. Moringa oleifera Lam. species, native from India, was chosen considering its rusticity and the increasing interest on this species due to its multiple uses, nutritional value, and medicinal properties. The first phase of this work was a compilation of data from climatic downscaling (WorldClim), University of East Anglia database (CRU), FAO database, and an historic datasets from Chilean meteorological stations. This information was used to test two different models to compare bioclimatic profiles, considering relevant climatic variables for plant adaptation: maximum and minimum temperatures, accumulated degree days, frost regime, and air humidity. The first approach, based on climatic analogy, was to compare each of these variables between Chilean and foreign localities, and the second, based on bioclimatic suitability, focus on the degree of meeting the minimum bioclimatic requirements by the species in each locality. This paper provides some tools to make this kind of comparisons. Both approaches were tested using $M$. oleifera as target. Both approaches were complementary and prove to be useful for identifying potential areas where the species could be cultivated. The use of these approaches suggested the existence of some bioclimatic suitability for this species in the coastal areas with mild winters and frosts, from $27^{\circ}$ to $37^{\circ} \mathrm{S}$ lat.
\end{abstract}

Key words: Bioclimatic suitability, germplasm adaptability, germplasm evaluation, moringa.

\section{INTRODUCTION}

Adaptability of a particular species to a new area of cultivation is generally assessed by mean of costly trial and error experimental plots distributed throughout different bioclimatic environments. At present, there is an increasing interest in developing methods to understand the ecophysiological basis of plant ecology, in order to improve our capacity to understand the potential effects of climate change in modifying geographic distribution of species (Chabot and Mooney, 1985). Presently, climatic data are available from global models and downscaling, enabling the construction of high resolution climatic maps (Xiaojun et al., 2011), which can be tested with local bioclimatic weather stations and satellite information (Hijmans et al., 2005). This data can be used to predict the performance of any species in a new environment, provided that quality databases are available.

${ }^{1}$ Universidad Chile, Facultad de Ciencias Agronómicas, Casilla 1004, Santiago, Chile. *Corresponding author (fsantiba@uchile.cl). Received: 10 December 2014.

Accepted: 30 July 2015.

doi:10.4067/S0718-58392015000500007
There is a recent interest in the introduction and evaluation of this species that could help in the diversification of Chilean agriculture, especially in marginal and degraded areas. Moringa (Moringa oleifera Lam.) belong to the family Moringaceae, native from the Northwestern India (Da Silva et al., 2014), adapts well to rustic soils. Common names for the species include moringa, drumstick tree, horseradish tree, and miracle tree. It is a fast-growing medium-size tree, which has been recently domesticated and introduced for cultivation in marginal lands of tropical and subtropical dry areas, where other agricultural crops are restricted (Nouman et al., 2014). But, its cultivation has also been extended to Southeast Asia, the Arabian Peninsula, tropical Africa (Parrotta, 2009), Australia (Navie and Csurhes, 2010), and America, from Mexico to Peru, the Caribbean and Florida (Paliwal et al., 2011), and in the Arid Chaco of Northern Western Argentina (Ayerza, 2011).

The species has attracted increasing interest because of its many uses and properties (Anwar et al., 2007). It is mainly valued for its edible pods, as potential source of biofuels and for its rich content of proteins (Salaheldeen et al., 2014). The leaves are also consumed as a fresh vegetable. Dried leaf powder can be added to all type of 
food as a nutritional supplement, due to its high content of vitamin C, $\beta$-carotene, and protein (Dubey et al., 2013) and as a resource for the extraction of plant hormones (de Saint Sauveur and Broin, 2010). Other uses of the species include oil extraction from seeds which containing until $70 \%$ of oleic acid (Rashid et al., 2008), food for animals, pharmacological applications, and flocculant mainly to purify water (Mishra et al., 2011).

The climate in the center of origin and diversification of the species in Northwestern India corresponds to the Cwa climate, which is a subtropical climate with a dry season, according to Koppen's classification. Drumstick tree adapt to a wide variety of climates ranging from -1 to $3{ }^{\circ} \mathrm{C}$ for the coldest month to 38 to $48{ }^{\circ} \mathrm{C}$ for the warmest month, with annual rainfall of at least $500 \mathrm{~mm}$ (Parrotta, 2009). Optimum production of leaves and fruits are attained with average daily temperatures between 26 and $40{ }^{\circ} \mathrm{C}$ (Adebayo et al., 2011). Observations made by Paliwal et al. (2011) suggest that plant growth is significantly reduced with temperatures below $20^{\circ} \mathrm{C}$ and grow well within the of annual temperatures range of 15 to $30{ }^{\circ} \mathrm{C}$. Other authors observed optimal growth between 18 and $35^{\circ} \mathrm{C}$ (Emongor, 2011). The same author describes this species as susceptible to frosts. When grown under non-irrigation conditions, the species survives well with annual rainfall ranging from 250 to $1500 \mathrm{~mm}$ (de Saint Sauveur and Broin, 2010); however, the authors indicate that supplemental irrigation is needed if the annual rainfall is less than $800 \mathrm{~mm}$.

From the agronomic standpoint, moringa may represent a new crop for particular areas of Chile, but because of the large bioclimatic diversity of the country (Leubert and Pliscoff, 2006; Santibáñez et al., 2014), these areas are difficult to identify. Therefore, the identification of potential areas of adaptation for this crop is key to further evaluate the potential acreage that can be cultivated with this species. We used two different protocols to do this: bioclimatic analogies were established between Chilean and foreign locations where moringa is native or where it is grown successfully, and additionally, a profile of the minimum bioclimatic requirements for growing this species was established to map its potential adaptability areas in Chile. The minimum threshold of each bioclimatic variable was derived from the present geographic distribution of this species. The objective of this research was to develop two bioclimatic approaches to evaluate Chilean climates in order to establish potential zones for growing this species.

\section{MATERIALS AND METHODS}

To determine the adaptability of moringa, databases available at the Center for Agriculture and Environment (AGRIMED), Facultad de Ciencias Agronómicas, Universidad de Chile, were used. These databases represent a grid that covers much of the Chilean territory and where each point condenses relevant bioclimatic information interpolated from a network of weather stations with reliable time series of information. These stations belong to the Dirección Meteorológica de Chile (DMC), Dirección General de Aguas (DGA), Instituto de Investigaciones Agropecuarias (INIA), various Chilean universities, and private entities. Each grid point has information on monthly averages and extremes of temperature, precipitation, air relative humidity, and solar radiation. This primary information was supplemented with derived variables such as evapotranspiration, degreedays, winter chilling hours, number of potential frosts, monthly water deficits and surpluses, and others.

\section{Potential growing areas determined using bioclimatic analogies of Chile with foreign locations where moringa thrives}

Foreign reports were used to determine the areas where the species is better adapted in the world, mainly in India, its center of origin, and Africa. Then using the on-line New_LocClim software (FAO, Rome, Italy; http://www.fao.org/nr/climpag/pub/en3_051002_en.asp) monthly data on temperature, precipitation, day length, and heliophany (sunshine hours throughout the day) were generated for each foreign location. This system generates the information through an interpolation of the "n" nearest stations with the nearest neighbor method (Hall et al., 2008). Using this method, data were generated for each foreign location similar to the one available in the Chilean databases.

The solar radiation at each site was estimated from heliophany data, using the Angstrom equation (Yorukoglu and Celik, 2006):

$$
G r=E r *\left(0.25+0.5 \frac{n}{N}\right)
$$

where $G r$ is global solar radiation, $E r$ is the extraterrestrial solar radiation or Angot value, which is a function of the latitude, $n$ is the real and $N$ the potential heliophany (actual and potential sunshine hours per day).

The degree-days for each location were calculated using a standardized table that provides an estimation of daily and monthly degree-days, combining monthly maximum and minimum mean temperature. This table was derived from hundreds of daily temperature curves used to calculate degree-days every $15 \mathrm{~min}$ and integrating the value across the full day. To prepare this degree-day table, meteorological stations between $27^{\circ} 30^{\prime}$ and $40^{\circ} 30^{\prime} \mathrm{S}$ lat, belonging to the integrated Chilean agrometeorological network were used. Daily temperature curves included coastal maritime, inland subcontinental, and highland bioclimatic regime (Andean ranges). A synthetic table was prepared to be used on degree-day calculation for bioclimatic comparisons (Table 1).

The number of frosts was estimated from the probability of having temperatures below $0{ }^{\circ} \mathrm{C}$, assuming a normal distribution of the daily minimum temperature within 
Table 1. Daily degree-days above $10{ }^{\circ} \mathrm{C}$ on the basis of daily temperature curve ( $\times 30$ for monthly accumulation).

Minimum temperature, ${ }^{\circ} \mathrm{C}$

\begin{tabular}{|c|c|c|c|c|c|c|c|c|c|c|c|c|c|c|c|c|c|c|c|c|}
\hline & 1 & 2 & 3 & 4 & 5 & 6 & 7 & 8 & 9 & 10 & 11 & 12 & 13 & 14 & 15 & 16 & 17 & 18 & 19 & 20 \\
\hline 11 & 0.2 & 0.2 & 0.2 & 0.2 & 0.2 & 0.2 & 0.2 & 0.3 & 0.3 & 0.5 & 1.0 & 1.5 & 2.0 & 2.5 & 3.1 & 3.6 & 4.1 & 4.6 & 5.1 & 5.6 \\
\hline 12 & 0.4 & 0.4 & 0.5 & 0.5 & 0.5 & 0.5 & 0.6 & 0.6 & 0.7 & 1.0 & 1.5 & 2.0 & 2.5 & 3.0 & 3.5 & 4.1 & 4.6 & 5.1 & 5.6 & 6.1 \\
\hline 13 & 0.7 & 0.7 & 0.8 & 0.8 & 0.8 & 0.9 & 1.0 & 1.0 & 1.2 & 1.5 & 2.0 & 2.5 & 3.0 & 3.5 & 4.0 & 4.5 & 5.1 & 5.6 & 6.1 & 6.6 \\
\hline 14 & 1.0 & 1.1 & 1.1 & 1.2 & 1.2 & 1.3 & 1.4 & 1.5 & 1.6 & 1.9 & 2.5 & 3.0 & 3.5 & 4.0 & 4.5 & 5.0 & 5.5 & 6.1 & 6.6 & 7.1 \\
\hline 15 & 1.4 & 1.4 & 1.5 & 1.5 & 1.6 & 1.7 & 1.8 & 1.9 & 2.1 & 2.4 & 2.9 & 3.5 & 4.0 & 4.5 & 5.0 & 5.5 & 6.0 & 6.5 & 7.1 & 7.6 \\
\hline 16 & 1.7 & 1.8 & 1.8 & 1.9 & 2.0 & 2.1 & 2.2 & 2.4 & 2.6 & 2.9 & 3.4 & 3.9 & 4.5 & 5.0 & 5.5 & 6.0 & 6.5 & 7.0 & 7.5 & 8.1 \\
\hline 17 & 2.1 & 2.2 & 2.2 & 2.3 & 2.4 & 2.5 & 2.6 & 2.8 & 3.0 & 3.4 & 3.9 & 4.4 & 4.9 & 5.5 & 6.0 & 6.5 & 7.0 & 7.5 & 8.0 & 8.5 \\
\hline 18 & 2.5 & 2.6 & 2.6 & 2.7 & 2.8 & 2.9 & 3.1 & 3.3 & 3.5 & 3.9 & 4.4 & 4.9 & 5.4 & 5.9 & 6.5 & 7.0 & 7.5 & 8.0 & 8.5 & 9.0 \\
\hline 19 & 2.9 & 3.0 & 3.0 & 3.1 & 3.3 & 3.4 & 3.5 & 3.7 & 4.0 & 4.4 & 4.9 & 5.4 & 5.9 & 6.4 & 6.9 & 7.5 & 8.0 & 8.5 & 9.0 & 9.5 \\
\hline 20 & 3.3 & 3.4 & 3.5 & 3.6 & 3.7 & 3.8 & 4.0 & 4.2 & 4.4 & 4.8 & 5.4 & 5.9 & 6.4 & 6.9 & 7.4 & 7.9 & 8.5 & 9.0 & 9.5 & 10.0 \\
\hline 21 & 3.7 & 3.8 & 3.9 & 4.0 & 4.1 & 4.3 & 4.4 & 4.6 & 4.9 & 5.3 & 5.8 & 6.4 & 6.9 & 7.4 & 7.9 & 8.4 & 8.9 & 9.5 & 10.0 & 10.5 \\
\hline 22 & 4.1 & 4.2 & 4.3 & 4.4 & 4.6 & 4.7 & 4.9 & 5.1 & 5.4 & 5.8 & 6.3 & 6.8 & 7.4 & 7.9 & 8.4 & 8.9 & 9.4 & 9.9 & 10.5 & 11.0 \\
\hline 23 & 4.5 & 4.6 & 4.7 & 4.9 & 5.0 & 5.2 & 5.3 & 5.6 & 5.9 & 6.3 & 6.8 & 7.3 & 7.8 & 8.4 & 8.9 & 9.4 & 9.9 & 10.4 & 10.9 & 11.5 \\
\hline 24 & 4.9 & 5.0 & 5.2 & 5.3 & 5.4 & 5.6 & 5.8 & 6.0 & 6.3 & 6.8 & 7.3 & 7.8 & 8.3 & 8.8 & 9.4 & 9.9 & 10.4 & 10.9 & 11.4 & 11.9 \\
\hline 25 & 5.4 & 5.5 & 5.6 & 5.7 & 5.9 & 6.1 & 6.3 & 6.5 & 6.8 & 7.3 & 7.8 & 8.3 & 8.8 & 9.3 & 9.8 & 10.4 & 10.9 & 11.4 & 11.9 & 12.4 \\
\hline 26 & 5.8 & 5.9 & 6.0 & 6.2 & 6.3 & 6.5 & 6.7 & 7.0 & 7.3 & 7.7 & 8.3 & 8.8 & 9.3 & 9.8 & 10.3 & 10.8 & 11.4 & 11.9 & 12.4 & 12.9 \\
\hline 27 & 6.2 & 6.3 & 6.5 & 6.6 & 6.8 & 7.0 & 7.2 & 7.5 & 7.8 & 8.2 & 8.7 & 9.3 & 9.8 & 10.3 & 10.8 & 11.3 & 11.8 & 12.4 & 12.9 & 13.4 \\
\hline 28 & 6.6 & 6.8 & 6.9 & 7.1 & 7.2 & 7.4 & 7.7 & 7.9 & 8.3 & 8.7 & 9.2 & 9.7 & 10.3 & 10.8 & 11.3 & 11.8 & 12.3 & 12.8 & 13.4 & 13.9 \\
\hline 29 & 7.1 & 7.2 & 7.3 & 7.5 & 7.7 & 7.9 & 8.1 & 8.4 & 8.7 & 9.2 & 9.7 & 10.2 & 10.7 & 11.3 & 11.8 & 12.3 & 12.8 & 13.3 & 13.8 & 14.4 \\
\hline 30 & 7.5 & 7.6 & 7.8 & 8.0 & 8.1 & 8.4 & 8.6 & 8.9 & 9.2 & 9.7 & 10.2 & 10.7 & 11.2 & 11.7 & 12.3 & 12.8 & 13.3 & 13.8 & 14.3 & 14.8 \\
\hline 31 & 7.9 & 8.1 & 8.2 & 8.4 & 8.6 & 8.8 & 9.1 & 9.4 & 9.7 & 10.2 & 10.7 & 11.2 & 11.7 & 12.2 & 12.7 & 13.3 & 13.8 & 14.3 & 14.8 & 15.3 \\
\hline 32 & 8.4 & 8.5 & 8.7 & 8.9 & 9.1 & 9.3 & 9.5 & 9.8 & 10.2 & 10.6 & 11.2 & 11.7 & 12.2 & 12.7 & 13.2 & 13.7 & 14.3 & 14.8 & 15.3 & 15.8 \\
\hline 33 & 8.8 & 9.0 & 9.1 & 9.3 & 9.5 & 9.8 & 10.0 & 10.3 & 10.7 & 11.1 & 11.6 & 12.2 & 12.7 & 13.2 & 13.7 & 14.2 & 14.7 & 15.3 & 15.8 & 16.3 \\
\hline 34 & 9.3 & 9.4 & 9.6 & 9.8 & 10.0 & 10.2 & 10.5 & 10.8 & 11.1 & 11.6 & 12.1 & 12.6 & 13.2 & 13.7 & 14.2 & 14.7 & 15.2 & 15.7 & 16.3 & 16.8 \\
\hline 35 & 9.7 & 9.9 & 10.0 & 10.2 & 10.5 & 10.7 & 11.0 & 11.3 & 11.6 & 12.1 & 12.6 & 13.1 & 13.6 & 14.2 & 14.7 & 15.2 & 15.7 & 16.2 & 16.7 & 17.3 \\
\hline 36 & 10.2 & 10.3 & 10.5 & 10.7 & 10.9 & 11.2 & 11.4 & 11.7 & 12.1 & 12.6 & 13.1 & 13.6 & 14.1 & 14.6 & 15.2 & 15.7 & 16.2 & 16.7 & 17.2 & 17.7 \\
\hline
\end{tabular}

each month and from the standard deviation, estimated from the average minimum temperature of each month. Standard deviation (SD) requires daily temperature data that is not always available. To overcome this difficulty we provide a table (Table 2) considering four situations:
A, coastal locations with high oceanic influence $(\mathrm{SD}=2)$; $\mathrm{B}$, inland location with medium temperature variability $(\mathrm{SD}=3) ; \mathrm{C}$, inland locations with high temperature variability $(S D=4)$ and $D$, continental locations with very high temperature variability $(\mathrm{SD}=5)$. Highland locations

Table 2. Estimation of the monthly number of frosts on the basis of minimum monthly temperature $\left({ }^{\circ} \mathrm{C}\right)$ and standard deviation $(\mathrm{SD})$ of daily minimum temperature.

(A) $\mathrm{SD}=2$ Oceanic areas

\begin{tabular}{|c|c|c|c|c|c|c|c|c|c|c|}
\hline & 0 & 0.1 & 0.2 & 0.3 & 0.4 & 0.5 & 0.6 & 0.7 & 0.8 & 0.9 \\
\hline 0 & 19.7 & 19.1 & 18.5 & 17.8 & 17.2 & 16.6 & 16.0 & 15.4 & 14.8 & 14.2 \\
\hline 1 & 8.4 & 7.9 & 7.5 & 7.1 & 6.7 & 6.3 & 5.9 & 5.5 & 5.2 & 4.9 \\
\hline 2 & 2.2 & 2.0 & 1.8 & 1.7 & 1.6 & 1.4 & 1.3 & 1.2 & 1.1 & 1.0 \\
\hline 3 & 0.3 & 0.3 & 0.3 & 0.2 & 0.2 & 0.2 & 0.2 & 0.2 & 0.2 & 0.2 \\
\hline 4 & 0.2 & 0.1 & 0.1 & 0.1 & 0.1 & 0.1 & 0.1 & 0.1 & 0.1 & 0.1 \\
\hline 5 & 0.1 & 0.1 & 0.1 & 0.1 & 0.0 & 0.0 & 0.0 & 0.0 & 0.0 & 0.0 \\
\hline 6 & 0.0 & 0.0 & 0.0 & 0.0 & 0.0 & 0.0 & 0.0 & 0.0 & 0.0 & 0.0 \\
\hline 7 & 0.0 & 0.0 & 0.0 & 0.0 & 0.0 & 0.0 & 0.0 & 0.0 & 0.0 & 0.0 \\
\hline (B) & $\mathrm{SD}=3$ & Inla & d, I & to & 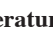 & van & ability & & & \\
\hline & 0 & 0.1 & 0.2 & 0.3 & 0.4 & 0.5 & 0.6 & 0.7 & 0.8 & 0.9 \\
\hline 0 & 19.7 & 19.3 & 18.8 & 18.4 & 17.9 & 17.5 & 17.0 & 16.6 & 16.2 & 15.7 \\
\hline 1 & 11.2 & 10.8 & 10.5 & 10.1 & 9.7 & 9.4 & 9.0 & 8.7 & 8.4 & 8.0 \\
\hline 2 & 5.0 & 4.8 & 4.5 & 4.3 & 4.1 & 3.9 & 3.7 & 3.5 & 3.4 & 3.2 \\
\hline 3 & 1.7 & 1.6 & 1.5 & 1.4 & 1.3 & 1.3 & 1.2 & 1.1 & 1.0 & 1.0 \\
\hline 4 & 0.4 & 0.4 & 0.4 & 0.4 & 0.3 & 0.3 & 0.3 & 0.3 & 0.2 & 0.2 \\
\hline 5 & 0.1 & 0.1 & 0.1 & 0.1 & 0.1 & 0.1 & 0.1 & 0.1 & 0.0 & 0.0 \\
\hline 6 & 0.1 & 0.1 & 0.1 & 0.0 & 0.0 & 0.0 & 0.0 & 0.0 & 0.0 & 0.0 \\
\hline 7 & 0.0 & 0.0 & 0.0 & 0.0 & 0.0 & 0.0 & 0.0 & 0.0 & 0.0 & 0.0 \\
\hline
\end{tabular}

(C) SD = 4 Inland, high temperature variability

$\begin{array}{rrrrrrrrrrr} & 0 & 0.1 & 0.2 & 0.3 & 0.4 & 0.5 & 0.6 & 0.7 & 0.8 & 0.9 \\ 0 & 19.7 & 19.4 & 19.0 & 18.7 & 18.3 & 18.0 & 17.6 & 17.3 & 16.9 & 16.6 \\ 1 & 13.0 & 12.6 & 12.3 & 12.0 & 11.7 & 11.4 & 11.1 & 10.8 & 10.5 & 10.2 \\ 2 & 7.4 & 7.2 & 6.9 & 6.7 & 6.5 & 6.3 & 6.1 & 5.8 & 5.6 & 5.5 \\ 3 & 3.6 & 3.5 & 3.3 & 3.2 & 3.1 & 2.9 & 2.8 & 2.7 & 2.6 & 2.5 \\ 4 & 1.5 & 1.4 & 1.4 & 1.3 & 1.2 & 1.2 & 1.1 & 1.1 & 1.0 & 1.0 \\ 5 & 0.5 & 0.5 & 0.5 & 0.4 & 0.4 & 0.4 & 0.4 & 0.3 & 0.3 & 0.3 \\ 6 & 0.2 & 0.1 & 0.1 & 0.1 & 0.1 & 0.1 & 0.1 & 0.1 & 0.1 & 0.1 \\ 7 & 0.1 & 0.1 & 0.1 & 0.0 & 0.0 & 0.0 & 0.0 & 0.0 & 0.0 & 0.0\end{array}$

(D) $\mathrm{SD}=5$ Continental, high temperature variability

$\begin{array}{rrrrrrrrrrr} & 0 & 0.1 & 0.2 & 0.3 & 0.4 & 0.5 & 0.6 & 0.7 & 0.8 & 0.9 \\ 0 & 19.7 & 19.4 & 19.2 & 18.9 & 18.6 & 18.3 & 18.0 & 17.7 & 17.4 & 17.2 \\ 1 & 14.1 & 13.9 & 13.6 & 13.3 & 13.1 & 12.8 & 12.6 & 12.3 & 12.1 & 11.8 \\ 2 & 9.2 & 9.0 & 8.8 & 8.6 & 8.4 & 8.2 & 8.0 & 7.8 & 7.6 & 7.4 \\ 3 & 5.4 & 5.3 & 5.1 & 5.0 & 4.8 & 4.7 & 4.5 & 4.4 & 4.3 & 4.1 \\ 4 & 2.9 & 2.8 & 2.7 & 2.6 & 2.5 & 2.4 & 2.3 & 2.2 & 2.2 & 2.1 \\ 5 & 1.4 & 1.3 & 1.3 & 1.2 & 1.2 & 1.1 & 1.1 & 1.0 & 1.0 & 0.9 \\ 6 & 0.6 & 0.6 & 0.5 & 0.5 & 0.5 & 0.5 & 0.4 & 0.4 & 0.4 & 0.4 \\ 7 & 0.2 & 0.2 & 0.2 & 0.2 & 0.2 & 0.2 & 0.2 & 0.2 & 0.1 & 0.1 \\ 8 & 0.1 & 0.1 & 0.1 & 0.1 & 0.1 & 0.1 & 0.1 & 0.1 & 0.1 & 0.0\end{array}$


above $2500 \mathrm{~m}$ normally have low temperature variability (SD 2 or 3).

From the available bibliographic information, five key variables were identified to better assess the potential adaptability of this species: the maximum temperature of the warmest month, the minimum temperature of coldest month, annual degree-days (Dd), relative humidity, and number of frosts. These variables were calculated in selected foreign areas suitable for this species (Table 3). Climates at the center of origin of this species have maximum temperatures during the growing cycle of 25 ${ }^{\circ} \mathrm{C}$ and minimum temperature of $15^{\circ} \mathrm{C}$. These thresholds were considered as close to the optimum for this species. The lower minimum temperature during the growing cycle was close to $10{ }^{\circ} \mathrm{C}$ and the higher minimum temperature, close to $25^{\circ} \mathrm{C}$. In the case of the maximum temperature, the highest was close to $35{ }^{\circ} \mathrm{C}$, and the lowest close to $18^{\circ} \mathrm{C}$.

Most plant species have $\mathrm{Q}_{10}$ values close to 2.0 (Owen and Tjoelker, 2003; Wythers et al., 2013), which mean that the respiration rate is halved when the temperature drops $10{ }^{\circ} \mathrm{C}$ below the optimal temperature. This reduces in about the same proportion the growth rate and the biomass production (Brown et al., 2004). Considering that respiration is the main driver of plant growth, we could suppose a proportional reduction on the growing rate which fit well with the empirical data provided by growth rate curves of most cultivated species, where the distance among minimum growing temperature (10 ${ }^{\circ} \mathrm{C}$ for most subtropical species) and optimum growing temperature $\left(30^{\circ} \mathrm{C}\right)$ is about $20^{\circ} \mathrm{C}$. This implies a growth rate of change of about $5 \%$ per degree Celsius for the suboptimal interval. In the case of the supra-optimal interval, the distance among optimal and maximal growing temperature $\left(40{ }^{\circ} \mathrm{C}\right)$ is close to $10{ }^{\circ} \mathrm{C}$, which suggest a rate of change of $10 \%$ per degree Celsius in the supraoptimal range. Considering the whole interval of growing temperature, between minimum and maximum growing temperature, a mean change of $7.5 \%$ of the growing rate per ${ }^{\circ} \mathrm{C}$ can be considered.

Table 3. Climatic characterization of foreign locations where moringa is well adapted.

\begin{tabular}{|c|c|c|c|c|}
\hline \multirow[b]{2}{*}{ Location } & \multicolumn{2}{|c|}{${ }^{\circ} \mathrm{C}$} & \multirow[b]{2}{*}{ Degree-day } & \multirow[b]{2}{*}{$\mathrm{Nr}$ of frosts } \\
\hline & $\mathrm{T}_{\max }$ & $\mathrm{T}_{\min }$ & & \\
\hline Nairobi, Kenya & 26.3 & 10.8 & 2.593 & 0 \\
\hline Tooseng, South Africa & 28.1 & 4.4 & 2.560 & 6 \\
\hline Gyalzing, India & 19.7 & 3.0 & 963 & 18 \\
\hline Ramnagar, India & 35.4 & 8.3 & 4.217 & 0 \\
\hline Namphada, India & 28.1 & 6.8 & 3.184 & 0 \\
\hline Nirjuli, India & 32.4 & 9.8 & 4.448 & 0 \\
\hline Sonapur, India & 31.7 & 10.5 & 4.492 & 0 \\
\hline Bareilley, India & 33.7 & 8.6 & 4.438 & 0 \\
\hline Dehradun, India & 30.3 & 6.0 & 3.468 & 1 \\
\hline Gorakhpur, India & 32.7 & 9.8 & 4.564 & 0 \\
\hline Shimla, India & 21.0 & 1.8 & 1.121 & 32 \\
\hline Keur Momar, Senegal & 30.7 & 15.1 & 5.448 & 0 \\
\hline Accra, Ghana & 27.2 & 22.7 & 5.679 & 0 \\
\hline Niamey, Niger & 34.0 & 16.1 & 5.977 & 0 \\
\hline Culiacan, Mexico & 35.7 & 12.3 & 5.313 & 0 \\
\hline
\end{tabular}

Each foreign location of reference was compared with the Chilean data, calculating variable by variable the positive or negative deviations in each of these five variables. As each variable was measured in different units, which were not equivalent, they should be standardized to make comparisons. To do this, significant deviation for each variable $(\delta s)$ was established. These unit diversions corresponded to a significant difference between two values of the same variable. Thus, all differences were measured in comparable units. Using this approach, an Index of Bioclimatic Analogy $\left(I_{b a}\right)$ was generated, assuming that two locations are similar if the sum of the absolute significant deviations is smaller, according to the following equation:

$$
I_{b a}=\frac{1}{n} \sum_{n=1}^{n-n v}\left[\frac{a b s\left(v \mathrm{e}_{n}-v \mathrm{c}_{n}\right)}{\delta \mathrm{s}_{n}}\right]
$$

where, $v e$ is the value of each variable in the foreign location, $v c$ is the value of the same variable in the Chilean location and $\delta s$ is the magnitude of the significant deviations for the $n$ variables. Considering that bioclimatic interactions are very complex, translation of climatic differences into ecophysiological effects are difficult to establish based on each climatic variable. A more systemic consideration requires the use of ecophysiological models that are not available for moringa. To overcome this difficulty the establishment of significant deviations, which represent big enough climatic variations, can be used to create changes in the adaptability of the species under evaluation. In the case of the thermal regime, we considered $2{ }^{\circ} \mathrm{C}$ as a significant difference, which represent about $15 \%$ of change in the growing rate. In the case of accumulated degree-days we considered 250 degree-days as a significant deviation. This amount represents about $10 \%$ to $15 \%$ of the total annual requirement of moringa. In several plant species, variations of this magnitude may cause significant phenological changes and reproductive disruptions (Liu et al., 2011).

The Chilean territory was divided in small quadrants corresponding to a regular $10 \times 10 \mathrm{~km}$ geographic grid. Using ArcGIS software (Esri, Redlands, California, USA), the climatic information of five selected variables was extracted from a detailed climatic cartography obtained by topoclimatic models that interpolate variables on the basis of topography (digital elevation model), distance to the coast, altitude and latitude. This database was provided by an ongoing project aimed to create high-resolution climatic maps for the Chilean territory (Vulnerability and Adaptation to Climate Extremes in the Americas, VACEA). The $I_{b a}$ index was calculated in each point of the geographic grid using several foreign locations. The smaller the $I_{b a}$ value the greater the bioclimatic analogy between two locations. The $I_{b a}$ resulting from this process was mapped with the ArcGIS 10 software, which allowed the identification of those Chilean locations that showed the highest degree of bioclimatic similarity with each one of the locations where moringa grows well abroad. 


\section{Potential growing areas determined using a bioclimatic profile meeting minimum requirements}

The target of this second approach was to establish the set of minimum climatic requirements of the species, based on the analysis of more restrictive zones were the species grow successfully. This allows the determination of a minimum set of climatic conditions required for an adequate growth of the species. Once established this set of conditions, the system searches for those Chilean locations that meet or are close to these conditions. To do this, bioclimatic requirements were established based on the information available in the literature and in the climatic characteristics of the areas of the world where moringa grows successfully. For each variable, three levels of compliance were established: (i) Restrictive, the value above which moringa probably will not grow; (ii) Limiting, a range of values within which there are some probability for moringa to grow; and (iii) Optimum, values above which moringa grows well, considering that there are at least some cultivated areas in the world having the same conditions. The minimum set of bioclimatic conditions for moringa is shown in Table 4.

At each point of the Chilean territory, we determined the months of the year that met the minimum conditions, which enable us to determine the period of the year suitable for moringa growth (Monthly Suitability Index, $S_{m}$ ). The $S_{m}$ index was assigned with a number, depending on the degree of compliance with the minimum climatic requirements, using the following evaluation scale: 0 , a month having at least one climatic variable within the restrictive range; 1 , a month having at least one climatic variable within the limiting or range; 2 , a month in which the minimum climatic requirements are fully met.

The score of each month is $S_{m}$ and, for the full year, in each point of the climatic grid (location) the Annual Suitability Index $\left(S_{a}\right)$ was established by accumulating monthly scores:

$$
S_{a}=\sum_{1}^{12} S_{m} / 24
$$

where the divisor 24 was used to normalize a 0-2 monthly scale (annual maximum of 24) to unitary score (annual maximum $=12$ ).

In many areas, however, there may be a summer period with good conditions for the growth of a particular species, but in winter, cold weather may threaten the survival of the species. To cope with this situation, the analysis should include a combination of the index for

Table 4. Minimum, limiting, and optimum bioclimatic requirements of moringa.

\begin{tabular}{lccc}
\hline Variable & Restrictive & Limiting & Optimum \\
\hline Maximum temperature, ${ }^{\circ} \mathrm{C}$ & $<15$ & $15-22$ & $>22$ \\
Minimum temperature, ${ }^{\circ} \mathrm{C}$ & $<6$ & $6-12$ & $>12$ \\
Number of frosts & $>15$ & $0-15$ & 0 \\
Relative humidity, $\%$ & $<30$ & $30-50$ & $>50$ \\
Annual degree days $\left(\mathrm{t}>10^{\circ} \mathrm{C}\right)$ & 1000 & & $>2500$ \\
\hline
\end{tabular}

both periods and, therefore, a winter survival index was also calculated. To calculate the Winter Survival Index $\left(W_{s i}\right)$, the assumption, based on the analysis of present cultivated areas, was made that moringa will not thrive in sites with more than 15 frost events in a year and that the species survival is optimal in places without frosts. Thus the $W_{s i}$ as calculated according the following relation:

$$
W_{s i}=\left(N_{t f}-N_{f}\right) / N_{t f}
$$

where, $N_{t f}$ is the number of maximum annual tolerated frosts by the species; $N_{f}$ is the number of frosts that occur each year at a particular site. The index varies among 1 (optimum condition) and 0 (maximum restriction). Locations with frost events higher than $N_{t f}$ were evaluated as $W_{s i}=0$, no negative values were considered. In the case of moringa $N_{t f}$ was estimated in 15 (maximum observed in cultivated areas).

Once $S_{a}$ and $W_{s i}$ were calculated, it was assumed that either one that fell out of the recommended ranges, completely abolish the bioclimatic suitability of a location to grow moringa. Taking these into consideration, a Bioclimatic Suitability Index $\left(I_{B S}\right)$ was calculated from the product of both values:

$$
I_{B S}=S_{a}-W_{s i}
$$

$I_{B S}$ was calculated at each grid point and mapped with ArcGIS to generate a spatial view of the areas with higher potential to grow moringa.

\section{RESULTS AND DISCUSSION}

Even being a subtropical species, moringa has some ecophysiological characteristics which relate well with Chilean climates. She tolerates moderate drought periods (Rivas et al., 2013), fresh but not cold winters, and high luminosity and recovers well from minor frost, but does not tolerate severe frosts. For these reasons, subtropical species do not have many problems in adapting to Mediterranean temperate climates, having milder winters, which is the case of central Chile. The main threat of moringa in central Chile is survival facing frosts, mainly those of polar characteristics which can reach temperatures as low as $-5{ }^{\circ} \mathrm{C}$ in lowlands and foothills of the Andean range. Despite this potential limitation, there are some coastal areas which combine continental and maritime attributes, allowing them to have hot summers together with mild winters. It seems that these areas could host successful Moringa plantations under irrigated conditions.

Potential growing areas determined using bioclimatic analogies of Chile with foreign locations where moringa thrives well

The range of world climates where moringa thrives well shows that this species has plasticity, allowing its adaptation to varying climatic conditions (Emongor, 2011). Some of the locations where the species is well adapted show similarities with coastal interior locations, having mild 
winters in the Chilean territory. These areas have warm summers due to declining sea air that passes through the coastal hills, warming during descent. Considering the annual basis, Chilean localities potentially suitably for moringa, have less accumulated degree-days compared with the zone of origin of this species. This is due to longer winter duration, season where the rate of degreeday accumulation markedly slows down in Chile. This fact could not be a real limitation considering that subtropical species have the capacity to induce a physiological cold acclimation after exposed to temperatures below $10^{\circ} \mathrm{C}$ for short periods. Several subtropical species may lower in some extent, its temperature requirements as consequence of this phenomenon (Gusta et al., 2005) when they are introduced in temperate climate. There are evidences that, outside their origin areas, plant species can grow and reproduce in places where they can satisfy their thermal requirements for at least some fraction of the temperature cycle (Criddle et al., 2005). For this reason, in many cases, maximum temperature is more important than mean temperature when analyzing climatic suitability for a specific species. Table 3 shows the bioclimatic profiles of some selected cultivated areas.

Cooler locations correspond to the foothills of the Himalayas, where it is not uncommon to find winters with temperatures below $5{ }^{\circ} \mathrm{C}$ as the average of the coldest month (Table 3). Despite this, the climates that more resemble some of the climates found in Chile correspond to Nairobi (Kenya) and Tooseng (South Africa), with Proximity Indices lower than 1.5, indicating a significant degree of analogy with some Chilean locations. Figures 1 and 2 show the values of Proximity Index of these locations along the Chilean territory located between Chañaral (26 20' S lat) and Angol (37 $50^{\circ}$ 'S lat). The maps show a consistent similarity of Nairobi with the coastal area of the Atacama Region, between Caldera and Chañaral, while Tooseng resembles the higher areas of the Copiapó and Vallenar valleys. The largest difference for both locations lies in the accumulated degree-days, which is considerably lower in Chile, while the number of frost in Chile tends to be somewhat higher. Overall, based on bioclimatic analogies, it can be concluded that in Chile, some coastal areas from Atacama to Biobío Regions having climatic proximity with Nairobi and Tooseng, may be suitable for commercial moringa plantations.

\section{Potential growing areas determined using a bioclimatic profile of minimum requirements}

The method based on bioclimatic analogies is quite safe, but sometimes it is likely that the reference locations may exceed the requirements of the species, as have been shown to occur with other species, when these types of comparisons are made. When two locations are bioclimatically similar, any species will grow successfully at both locations. Conversely, when two locations do not exhibit bioclimatic similarities, this does

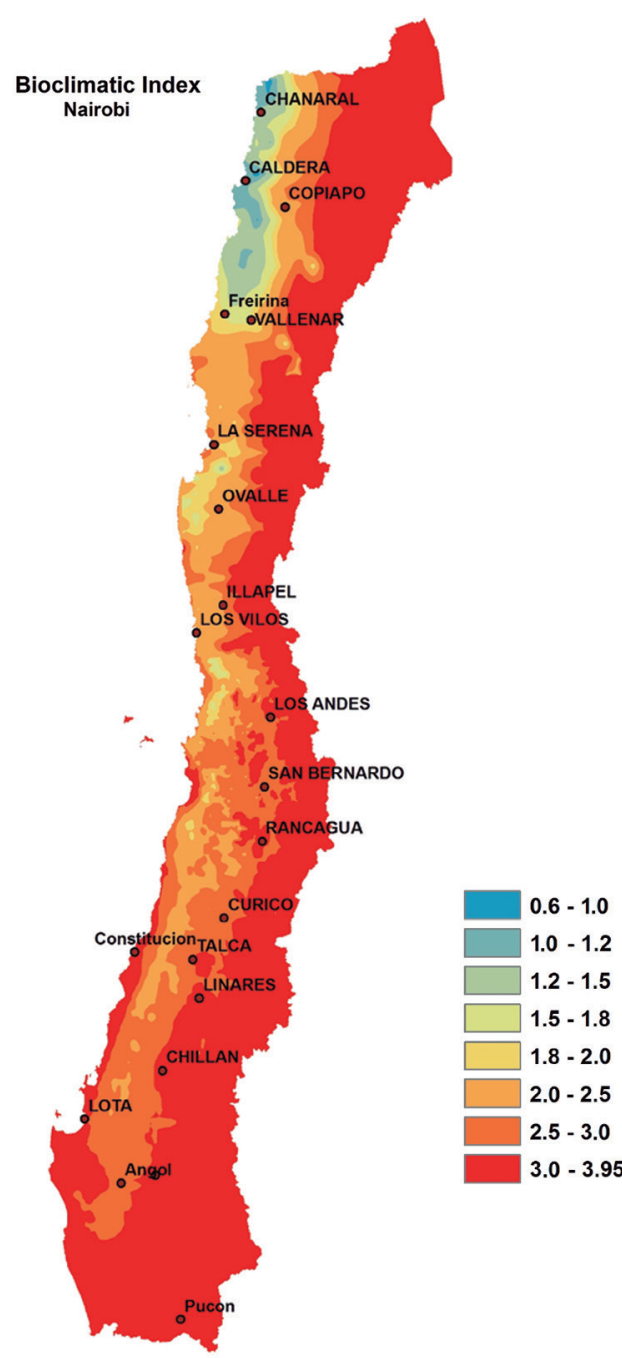

Figure 1. Map of bioclimatic analogy between Nairobi (Kenya) and Chile. Lower index means higher degrees of analogy with the foreign zone.

not exclude the possibility that a particular species can be successfully transferred to the other. This is due to the inherent adaptive plasticity that any given species may show. This issue has been systematically addressed by the bioclimatic modelers of plant distribution (Luoto et al., 2005; Heikkinen et al., 2006; Araújo and Peterson, 2012; Notaro et al., 2012; Booth, 2014). Normally envelope bioclimatic models tend to neglect the capacity of plant species to adapt to suboptimal climatic contexts.

To evaluate this second possibility, a different approach was used, where minimum thresholds of tolerance are determined for each climatic variable for a given species. These thresholds can be established based on experimental evidence or by looking at the most extreme climatic situations where the species thrives well within the current worldwide geographic adaptation of the species. This type of approach was used in Argentina (Falasca and Bernabé, 2009) to find possible areas of 


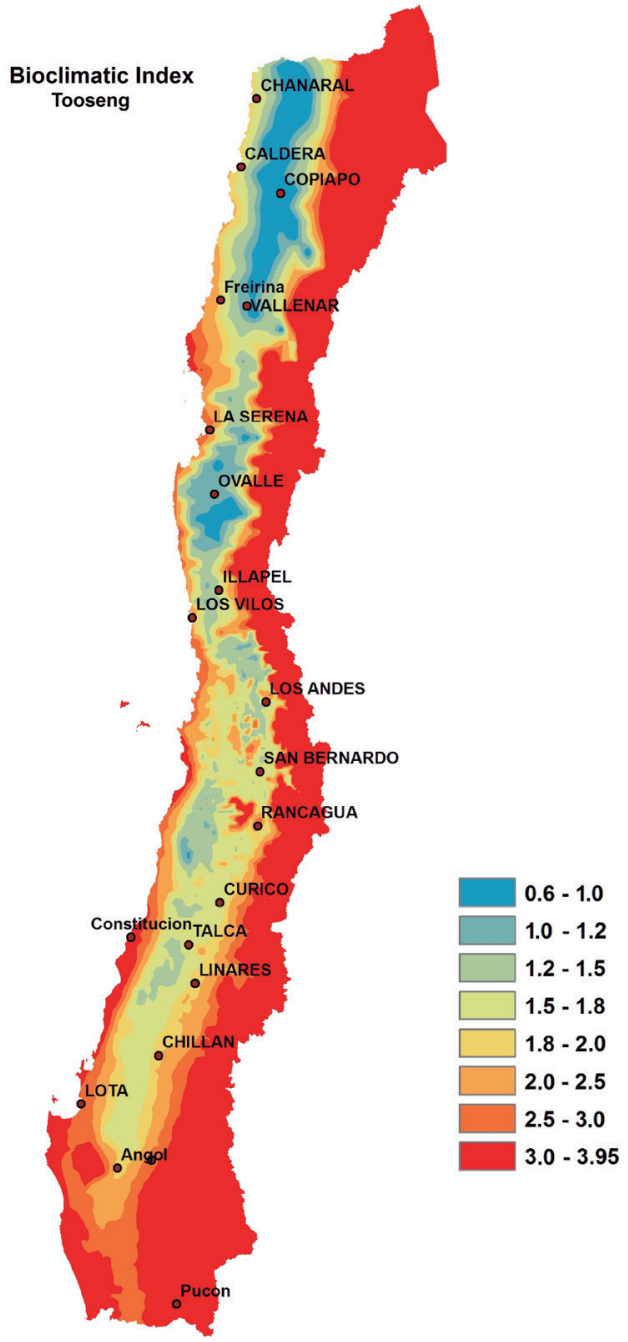

Figure 2. Map of bioclimatic analogy between Tooseng (South Africa) and Chile. Lower index means higher degrees of analogy with the foreign zone.

climatic adaptation for Moringa in the Provinces of Chaco, Corrientes, and Formosa. A similar approach was used in Spain (Godino et al., 2012) to find the potential area of moringa adaptation to the coast of Andalucía and Murcia.

To find the areas where moringa will be better adapted in Chile, the $S_{a}$, based on the fulfillment of minimum climatic requirements during the growing season, was calculated using a communal database. To further explore the potential areas of adaptability of the species, the $I_{B S}$ was calculated by multiplying $S_{a}$ by the $W_{s i}$ (Figure 3 ).

This analysis confirms the possibility of finding bioclimatically favorable areas in the coastal Regions of Atacama, Coquimbo, Valparaíso, Libertador General Bernardo O'Higgins and in the inner dry areas of the Region of Maule. All this locations show less available degree-days than the African and Asian locations, however, all these areas appear as locations where

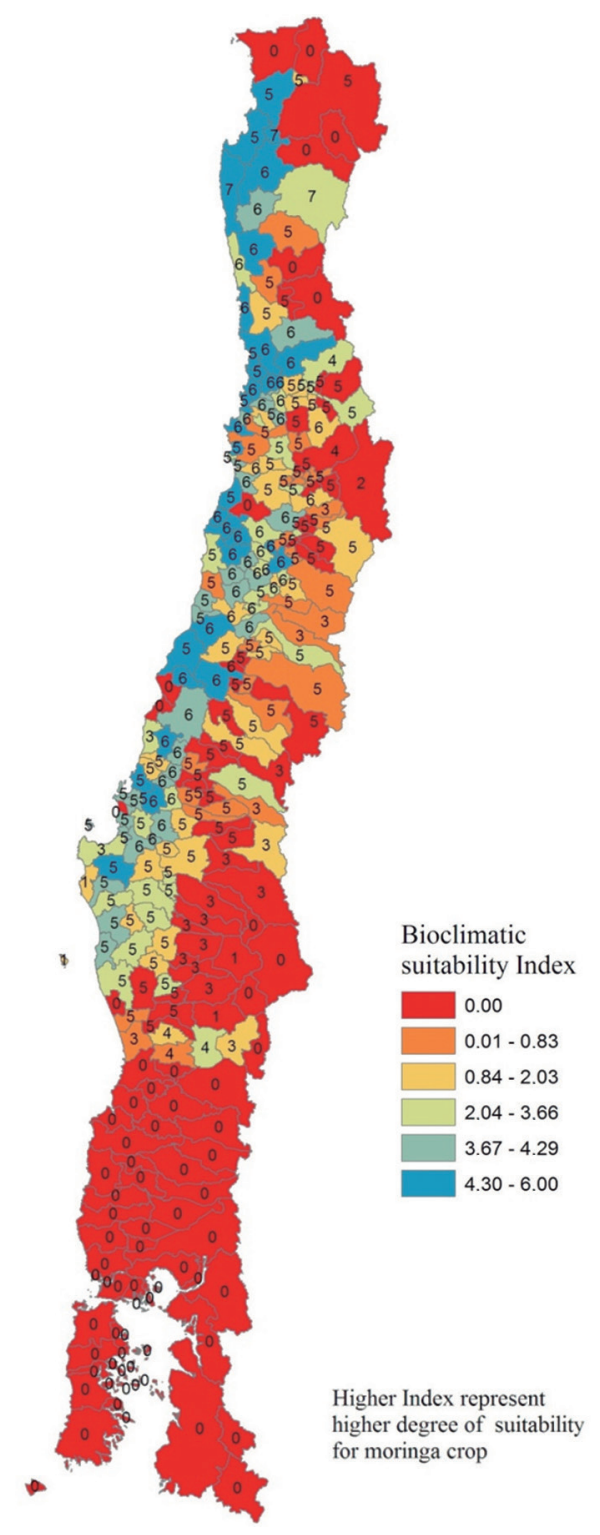

Numbers indicate number of months meeting the minimum bioclimatic requirements in each polygon (commune).

Figure 3. Bioclimatic suitability index. Reflects bioclimatic conditions during the growing season and winter survival possibilities. Higher index represents more suitability for moringa.

moringa adaptability is likely to occur. The reduced availability of degree-days should not be reflected in plant growth, but rather in the ability of the species to complete its reproductive cycle (producing fruits and seeds), which is not necessarily the goal when growing this species.

One limitation of this system is that it requires the availability of robust and reliable bioclimatic databases, which may not be available everywhere. When these databases are available, the system could also serve as an indicator for monitoring changes in the bioclimatic environment of a given species due to the climate change that is gradually occurring in most parts of the world 
(IPCC, 2013). Also, these indices allow to establish areas where a given species could be cultivated outdoors without problems (if having a growing season longer enough and high possibilities of winter survival) or where some type of crop protection is required for the success of the crop (if winter survival is unlikely).

\section{CONCLUSIONS}

The proposed systems, based on simple and robust bioclimatic indices, shows great potential for estimating the potential adaptability of a given species to a particular environment. The Bioclimatic Potential Index, based on the meeting of the minimum bioclimatic requirements of a species, allows the evaluation of the chances of success in the introduction of a given species to a new area. The underlying hypothesis of this approach is that for the biological success of a species, it is sufficient that the minimum requirements are met for all determinant variables. The second approach, looking for multiparametric identity among two locations or bioclimatic analogy, does not indicate very close similarities between Chilean locations and locations where moringa grows satisfactorily in different areas of the world. Despite this fact, there are several areas in Chile that meets all the minimum bioclimatic requirements of the species during several months. This indicates that this species could have, in these areas, a period long enough to be productive. The bioclimatic suitability index resumes the existence of a viable growing period, with a mild frost regime allowing the plant to survive the winter. According this index, the areas that show the largest potential for the adaptability of this species include some coastal areas with mild winters from $27^{\circ}$ to $37^{\circ} \mathrm{S}$ lat.

\section{ACKNOWLEDGEMENTS}

We acknowledge the financial support of the Fondo para la Innovación Competitiva, Región Metropolitana de Chile (project FIC-R 30110662).

\section{LITERATURE CITED}

Adebayo, A., H.A. Akintoye, A.O. Olufolaji, O.O. Aina, M.T. Olatunji, and A.O. Shokalu. 2011. Assessment of organic amendments on vegetative development and nutrient uptake of Moringa oleifera Lam. in the nursery. Asian Journal of Plant Sciences 10(1):74-79. doi:10.3923/ajps.2011.74.79.

Anwar, F., S. Latif, M. Ashraf, A. Hassan, and A.H. Gilani. 2007. Moringa oleifera: a food plant with multiple medicinal uses. Phytotherapy Research 21:17-25. doi:10.1002/ptr.2023.

Araújo, M.B., and T. Peterson. 2012. Uses and misuses of bioclimatic envelope modelling. Ecology 93:1527-1539. http://dx.doi. org/10.1890/11-1930.1.

Ayerza, R. 2011. Seed yield components, oil content, and fatty acid composition of two cultivars of moringa (Moringa oleifera Lam.) growing in the Arid Chaco of Argentina. Industrial Crops and Products 33:389-394.
Booth, T.H. 2014. Using biodiversity databases to verify and improve descriptions of tree species climatic requirements Forest Ecology and Management 315:95-102.

Brown, J.H., J.F. Gillooly, A.P. Allen, Van M. Savage, and G.B. West. 2004. Towards a metabolic theory of ecology. Ecology 85:17711789. http://dx.doi.org/10.1890/03-9000.

Chabot, B., and H.A. Mooney (ed.) 1985. Physiological ecology of North American plant communities. Chapman and Hall Ltd., London, UK.

Criddle, R.C., L.D. Hansen, B.N. Smith, C. Macfarlane, J.N. Church, T. Thygerson, et al. 2005. Thermodynamic law for adaptation of plants to environmental temperatures. Pure and Applied Chemistry 77:1425-1444.

de Saint Sauveur, A., and M. Broin. 2010. Growing and processing Moringa leaves. Moringanews, Moringa Association of Ghana. Available at http://miracletrees.org/moringa-doc/moringa_book_ growing_and_processing_moringa_leaves.pdf (accessed July 2015).

Da Silva, G., D. Souza de Oliveira, L. Calheiros de Oliveira, J. Vilanova, J. Belmino dos Santos, and G. Gama. 2014. Moringa oleifera Lam. Identification of opportunities for the Brazilian market through patent landscape analysis. Geintec 4:925-939. doi:10.7198/S2237-0722201400020019.

Dubey, D.K., J. Dora, A. Kumar, and R.K. Gulsan. 2013. A multipurpose tree Moringa oleifera. International Journal of Pharmaceutical and Chemical Sciences 2:415-423.

Emongor, V.E. 2011. Moringa (Moringa oleifera Lam.): A review. Acta Horticulturae (ISHS) 911:497-508.

Falasca, S., y M. Bernabé. 2009. Zonificación agroclimática de la moringa (Moringa oleifera) en Argentina para producir biodiesel y bietanol. Avances en Energías Renovables y Medio Ambiente 13:65-70.

Godino, M., S. Villegas, M.I. Izquierdo, J.C. Velásquez, y R. Vargas. 2012. Evaluación del uso energético de la Moringa oleifera. Agroforestería Neotropical 2:48-58.

Gusta, L.V., R. Trischuk, and C.J. Weiser. 2005. Plant cold acclimation: The role of abscisic acid. Journal of Plant Growth Regulation 24:308-318.

Hall, P., B.U. Park, and R.J. Samworth. 2008. Choice of neighbor order in nearest-neighbor classification. Annals of Statistics 36:2135-2152.

Heikkinen, R.K., M. Luoto, M.B. Araújo, R. Virkkala, W. Thuiller, and M.T. Sykes. 2006. Methods and uncertainties in bioclimatic envelope modelling under climate change. Progress in Physical Geography 30:751-777.

Hijmans, R.J., S.E. Cameron, J.L. Parra, P.G. Jones, and A. Jarvis. 2005. Very high resolution interpolated climate surfaces for global land areas. International Journal of Climatology 25:1965-1978.

IPCC. 2013. The Physical Science Basis, Working Group I. Fifth Assessment Report of the Intergovernmental Panel on Climate Change (IPCC), Cambridge University Press, Cambridge, UK.

Leubert, F., y P. Pliscoff. 2006. Sinopsis bioclimática y vegetacional de Chile. 316 p. Editorial Universitaria, Santiago, Chile.

Liu, Y., P.B. Reich, G. Li, and S. Sun. 2011. Shifting phenology and abundance under experimental warming alters trophic relationships and plant reproductive capacity. Ecology 92:12011207. http://dx.doi.org/10.1890/10-2060.1.

Luoto, M., J. Pöyry, R.K. Heikkinen, and K. Saarinen. 2005. Uncertainty of bioclimate envelope models based on the geographical distribution of species. Global Ecology and Biogeography 14:575-584.

Mishra, G., P. Singh, R. Verma, S. Kumar, S. Srivastav, K. Jha, et al. 2011. Traditional uses, phytochemistry and pharmacological properties of Moringa oleifera plant: An overview. Der Pharmacia Lettre 3:141-164.

Navie, S., and S. Csurhes. 2010. Weed risk assessment: Moringa oleifera. 26 p. Queensland Department of Employment, Economic Development and Innovation, Brisbane, Queensland, Australia. 
Notaro, M., A. Mauss, and J.W. Williams. 2012. Projected vegetation changes for the American Southwest: combined dynamic modeling and bioclimatic-envelope approach. Ecological Applications 22:1365-1388.

Nouman, W., S.M.A. Basra, M.T. Siddiqui, A. Yasmeen, T. Gull, and M.A.C.A. Alcayde. 2014. Potential of Moringa oleifera L. as livestock fodder crop: a review. Turkish Journal Agriculture and Forestry 38:1-14.

Owen, A., and M. Tjoelker. 2003. Thermal acclimation and the dynamic response of plant respiration to temperature. Trends in Plant Science 8:343-351.

Paliwal, R., V. Sharma, and J. Pracheta. 2011. A review on horse radish tree (Moringa oleifera): A multipurpose tree with high economic and commercial importance. Asian Journal of Biotechnology 3:317-328.

Parrotta, J. 2009. Moringa oleifera Lam. In Roloff, A., H. Weisgerber, U. Lang, B. Stimm (eds.) Enzyklopädie der Holzgewächse, Handbuchund. Atlas der Dendrologie 40. 8 p. Wiley-VCH Verlag $\mathrm{GmbH} \& \mathrm{Co}$, Weinheim, Germany.

Rashid, U.F., F. Anwar, B.R. Moser, and G. Knothe. 2008. Moringa oleifera oil: A possible source of biodiesel. Bioresource Technology 99:8175-8179.

Rivas, R., M.T. Oliveira, and M.G. Santos. 2013. Three cycles of water deficit from seed to young plants of Moringa oleifera woody species improves stress tolerance. Plant Physiology and Biochemistry 63:200-208.
Santibáñez, F., P. Santibáñez, C. Caroca, P. Morales, P. González, N. Gajardo, et al. 2014. Atlas del cambio climático en las zonas de régimen árido y semiárido: regiones de Coquimbo, Valparaíso y Metropolitana (Chile). 136 p. Universidad de Chile, Centro de Agricultura y Medio Ambiente, Santiago, Chile.

Salaheldeen, M., M.K. Aroua, A.A. Mariod, S.F. Cheng, and M.A. Abdelrahman. 2014. An evaluation of Moringa peregrina seeds as a source for bio-fuel. Industrial Crops and Products 61:49-61.

Wythers, K.R., P.B. Reich, and J.B. Bradford. 2013. Incorporating temperature-sensitive $\mathrm{Q}_{10}$ and foliar respiration acclimation algorithms modifies modeled ecosystem responses to global change. Journal of Geophysical Research: Biogeosciences 118:77-90

Yorukoglu, M., and A. Celik. 2006. A critical review on the estimation of daily global solar radiation from sunshine duration. Energy Conversion and Management 47:2441-2450.

Xiaojun, K., L. Qin, and L. Shirong. 2011. High-resolution bioclimatic dataset derived from future climate projections for plant species distribution modeling. Ecological Informatics 6:196-204 